\title{
A Novel Time Lag Method to Measure the Permeation of Vapor-Gas Mixtures
}

\author{
Jiahui Chen ${ }^{1}$, Leslie S. Loo ${ }^{1}$ and Kean Wang ${ }^{2, *}$ \\ ${ }^{1}$ School of Chemical and Biomedical Engineering, Nanyang Technological University, Singapore 637459 \\ ${ }^{2}$ Department of Chemical Engineering, The Petroleum Institute, Abu Dhabi, United Arab Emirates
}

\begin{abstract}
A novel time lag method was proposed to study the permeation of gas mixtures or vapor-gas mixtures. This technology, which is based on the difference in the boiling points of the components, can simultaneously measure the mass transport properties of each component. The permeation of a binary mixture of $\mathrm{H}_{2} \mathrm{O}(\mathrm{v}) / \mathrm{CO}_{2}$ was measured on a composite polymer membrane to demonstrate the feasibility of the technology. The method is low-cost and convenient for the future study of the permeation/separation of such gas mixtures as natural gas, flue gas, etc.
\end{abstract}

Keywords: Time lag, permeation, separation, mass transport.

\section{INTRODUCTION}

The time lag method is an important tool to study the mass transport in membranes/porous media because it enables us to measure the system properties at both the transient state (diffusion coefficient) and the steady state (permeability) [1]. Time lag analysis also represents an excellent example of mathematical interpretation of a physical process. Since the 'Method of Frisch' was proposed [1], a number of research progresses have been made with time lag analysis on such aspects of: concentration dependent diffusion coefficient [2], spatial/time dependent diffusion coefficients [3], the effect of isotherm and membrane geometry [4, 5], structural heterogeneity [6], and blind pore characteristics [7], etc..

A conventional time lag experimental rig consists of upstream and downstream vessels separated by a membrane cell. The pressures in the upstream and downstream vessels are monitored continuously by pressure transducers, respectively. The pressure response at the downstream vessel is usually employed for the time lag analysis. The membrane is generally 'clean' (or free of permeants) at the beginning of permeation, although desorption time lag (where the membrane is pre-equilibrated with gas permeants) is also a feasible operation mode [2].

Traditional time lag technology is limited to measure the permeation of a pure gas. For a binary or

\footnotetext{
${ }^{*}$ Address correspondence to this author at the Department of Chemical Engineering, The Petroleum Institute, Abu Dhabi, United Arab Emirates; Tel: 971-26075116; E-mail: kwang@pi.ac.ae

multicomponent gas mixture, the diffusion cell
}

technology is used (e.g. a Wicke-Kallenbach cell) [8], in which an inert gas (e.g. helium) is used as the 'sweeping gas' at the downstream to carry the permeants to a gas chromatography (GC) or mass spectrometry (MS) for the composition analysis. Such a device has a number of issues. Firstly, helium is a highly permeable gas. The chemical potential gradient may drive helium back to the upstream vessel, which interfere/interact with the forward-diffusing molecules. Secondly, GC/MS is time consuming and expensive. Thirdly, such a device is more suitable for the measurement of steady state, rather than the transient state.

To overcome the defects of the traditional time lag or diffusion cell, this research proposes a simplified solution to measure the permeation of gas or vapor-gas mixtures. It requires only minimal modification of a traditional time lag rig and is capable of measuring the permeation properties of both the transient and steady states.

\section{EXPERIMENTAL}

The traditional time lag rig is modified by adding a cold trap around the downstream vessel. By controlling the temperature of the cold trap, one species (e.g., the vapor) can be condensed into liquid or solid phase while the other species (e.g., the gas) still remains in the gas phase. In this way, the pressure response of the mixture and the vapor can be monitored and studied separately (with assumptions). The schematic diagram of the system is shown in Figure 1. Comparing with the diffusion cell technology, this method requires little extra resources and does not disturb the membrane cell. In our experimental rig, the upstream 
and downstream vessels are Teflon-lined with the volumes of $\sim 1,120 \mathrm{~cm}^{3}$ and $\sim 170 \mathrm{~cm}^{3}$, respectively. The temperature of the cold trap can be manipulated via a commercial Thermosat (Temperature range: -40 to $200^{\circ} \mathrm{C}$ ). The cold trap can also be conveniently maintained at the dry ice $\left(-78^{\circ} \mathrm{C}\right)$ or liquid nitrogen ($196^{\circ} \mathrm{C}$ ) temperature.

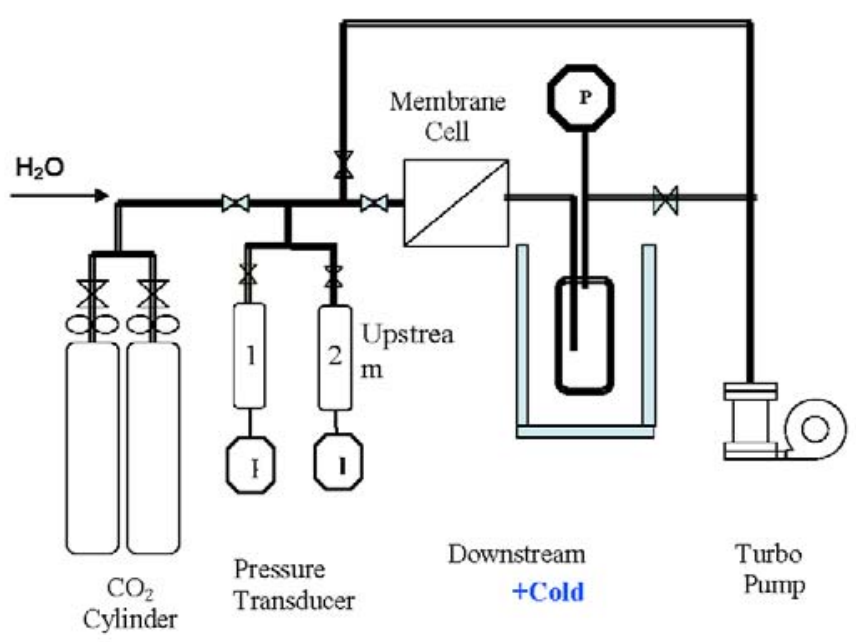

Figure 1: Schematic diagram of the improved permeation rig.

To demonstrate the feasibility of this technology, the permeations of binary mixtures of water vapor- $\mathrm{CO}_{2}$ were studied on a chitosan-POSS (polyhedral oligomeric silsesquioxanes) nanocomposite membrane. The membrane, which was obtained by blending $6 \mathrm{wt} \%$ of POSS into chitosan solution and followed by solution casting, was in the shape of a thin film with a diameter of $2.54 \mathrm{~cm}$ and a thickness of $20 \mu \mathrm{m}$. The adsorbed water molecules will 'assist' the permeation of gas molecules because the hydrophilic chitosan matrix swell under the humid conditions and even possibly open additional 'diffusion path' to facilitate the permeation of such gases as $\mathrm{N}_{2}, \mathrm{O}_{2}$ or $\mathrm{CO}_{2}$, etc. $[9,10]$. The purpose of adding hydrophilic POSS (type octaanion or $O A$ ) is to increase the mechanical strength and selectivity of the native chitosan membrane. The effects of the POSS content on chitosan membranes have been discussed in other studies [11, 12].
The permeation experiments were conducted at room temperature $\left(25^{\circ} \mathrm{C}\right)$. The system was first evacuated by a turbo molecular pump to a high vacuum of $\sim 10^{-4}$ torr. The membrane, upstream and downstream vessels were then isolated by turning off the corresponding valves in Figure 1. Next, water vapor was charged to vessel 1 (with the volume of $\sim 500 \mathrm{~cm}^{3}$ ) to the desired pressure and was then isolated. $\mathrm{CO}_{2}$ gas was charged into the upstream vessel 2 (with the volume of $\sim 500 \mathrm{~cm}^{3}$ ) to the designated pressure. Care was taken to prevent the condensation of water vapor when the two components were mixed (i.e. the partial pressure of water vapor is below its saturation pressure at that temperature). A heating source was used to mildly heat up the two vessels to assist the mixing/ diffusion over a long period of time ( 40 mins). Binary mixtures of water- $\mathrm{CO}_{2}$ were premixed in the two upstream vessels and were used in the subsequent permeation experiments. Table 1 lists the composition of the binary mixture after mixing. The permeation experiments followed the order of: pure $\mathrm{CO}_{2}$, binary mixture, and pure water. After each run, the membrane was cleaned by vacuuming. Finally, the spent membrane was cleaned and tested for $\mathrm{CO}_{2}$ permeation again to make sure it is pinhole free at dry condition.

The total pressure and the partial pressure of each component in Table $\mathbf{1}$ were calculated based on ideal gas assumption. During the experiments, the pressures in upstream and downstream vessels were monitored continuously and recorded in an Agilent ${ }^{\circledR}$ data logger. The steady-state permeation flux is calculated from the gradient of pressure-time response, $\mathrm{dP} / \mathrm{dt}$, of the downstream vessel [13], as shown in Eq. (1).

$$
J_{\infty}=\frac{1}{S} \frac{d n}{d t}=\frac{1}{S}\left(\frac{V}{R T} \times \frac{d P}{d t}\right)
$$

Where $\mathrm{J}$ is the flux $\left(\mathrm{mol} / \mathrm{m}^{2} \cdot \mathrm{s}\right), \mathrm{V}$ is the volume of downstream vessel $\left(\mathrm{m}^{3}\right)$, and $S$ is the membrane area $\left(\mathrm{m}^{2}\right)$.

Table 1: Compositions of the Binary Water- $\mathrm{CO}_{2}$ Mixtures

\begin{tabular}{|c|c|c|c|c|}
\hline \multirow{2}{*}{ Mixture No } & \multirow{2}{*}{ Total Pressure (torr) } & \multicolumn{2}{|c|}{ Partial Pressures (torr) } & \multirow{2}{*}{ Percentage Humidity (\%) } \\
\cline { 3 - 5 } & & Water & $\mathbf{C O}_{2}$ & \\
\hline \hline 1 & 12.1 & 8.9 & 3.2 & $37.5 \%$ \\
\hline 2 & 89.7 & 9.4 & 80.3 & $39 \%$ \\
\hline
\end{tabular}

Note: Percentage humidity = partial pressure of water vapor/saturated vapor pressure of water. 
The permeation fluxes of water and $\mathrm{CO}_{2}$ can be derived from the slopes before and after the condensation point, respectively.

\section{RESULT AND DISCUSSION}

The permeation of pure water vapor in the chitosanPOSS membrane is shown in Figure 2. The upstream pressure was charged to 23.8 torr with the water vapor (i.e. the saturated water vapor pressure at $25^{\circ} \mathrm{C}$ ). The cold trap was kept at $-14.5^{\circ} \mathrm{C}$. It is observed that even the membrane is highly hydrophilic, it took $\sim 900 \mathrm{~s}$ for water molecules to reach the quasi-steady state with a time lag of $630 \mathrm{~s}$. This slow permeation process is attributed to the fact that the membrane swells constantly before the final quasi-steady state [11]. Therefore, the permeation flux rather than permeability (which is the flux normalized to the thickness of the membrane) is used in this study.

The phase change (vapor to ice) of the water can be clearly identified in the downstream vessel. The hump in Figure 2 is due to the fact that water vapor was over-saturated to $\sim 1.6$ torr before the condensation took place and stabilized at a pressure of $\sim 1.3$ torr, which is the saturated vapor pressure of ice at the cold trap temperature [14].

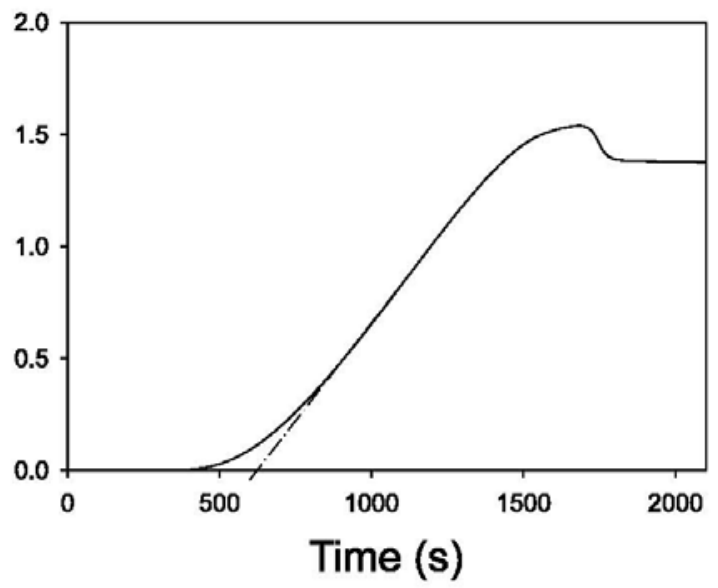

Figure 2: Permeation of pure water vapor.

The CS-POSS membrane was found to be impermeable (or undetectable) to pure $\mathrm{CO}_{2}$ gas at dry conditions, although literature suggested that $\mathrm{CO}_{2}$ has a marginal solubility $\left(\sim 10^{-4}\right.$ Barrer $)$ in pure CS membrane [12, 15]. However, the chitosan-based membrane has been known to lose this gas barrier property at high humidity. To investigate this phenomenon, Mixture 1 was tested. Figure $\mathbf{3}$ shows the pressure response at the downstream vessel. It is seen that the overall time lag increased to $\sim 1,400 \mathrm{~s}$, which is about twice that of the pure water vapor on the same membrane. Furthermore, no appreciable amount of $\mathrm{CO}_{2}$ penetrated the membrane at this humidity (a percentage humidity of $37.5 \%$ ), because there is no perceivable pressure incremental after the system reached steady state after $\sim 6,500 \mathrm{~s}$. This suggests that, at this feed condition, the membrane swells marginally and slowly compared with pure water vapor so that the water flux is decreased while $\mathrm{CO}_{2}$ is impermeable.

Despond et al. [9] investigated the adsorption and permeation of water vapor in native chitosan film and found that, when the relative water vapor pressure $\left(P / P_{0}\right.$, where $P_{0}$ is the saturated vapor pressure of water at that temperature) is below 0.4 , the sorption capacity and permeability of the membrane were generally low. When $\mathrm{P} / \mathrm{P}_{0}$ exceeded 0.4 , however, they were significantly increased due to the plasticization effect. However, it should be noted that our membrane is a composite of chitosan-POSS. Compared with native chitosan membrane, it has the lower degree of swelling and higher selectivity for the water-ethanol solutions [11]. Therefore, it is impermeable to $\mathrm{CO}_{2}$ at the feed condition of Mixture 1.

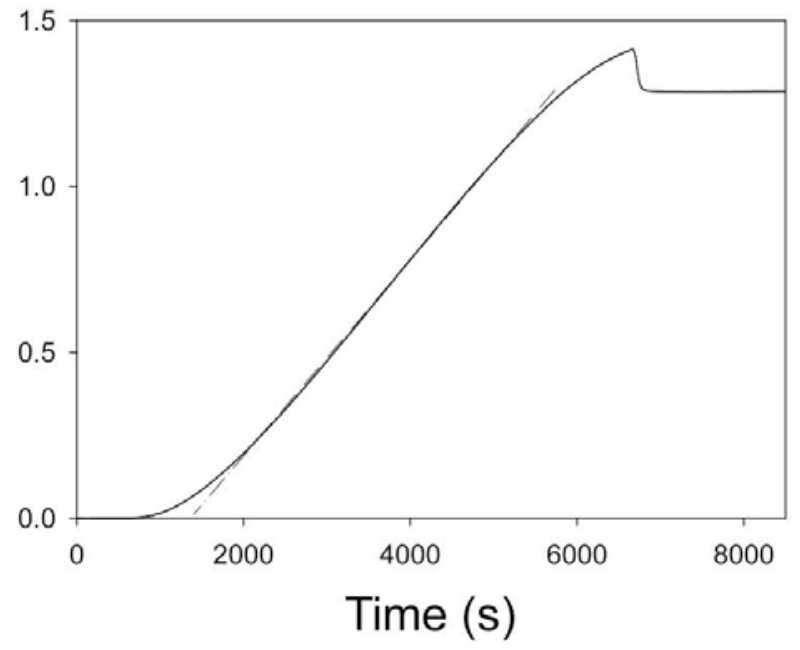

Figure 3: Permeation of Mixture 1 of water (8.9 torr) $-\mathrm{CO}_{2}$ (3.2 torr).

Finally, the partial pressure of $\mathrm{CO}_{2}$ gas was increased in the Mixture 2, which has the composition of [water (9.4 torr) $-\mathrm{CO}_{2}$ (80.3 torr)] and an increased humidity of $39 \%$. The permeation results are shown in Figure 4. It is noted that $\mathrm{CO}_{2}$ permeation is significant at this feed condition, because the downstream pressure rises significantly after the condensation point. 
The increase in $\mathrm{CO}_{2}$ permeation is mainly attributed to its higher partial pressure in permeant gas mixture, which exerts a higher driving force for its diffusion and a high adsorbed concentration in the swollen membrane. It has been demonstrated that $\mathrm{CO}_{2}$ has a solubility comparable to that of water vapor $[12,15]$ in chitosan and may cause plasticization of CS. Due to the stronger interaction between $\mathrm{CO}_{2}$ and water molecules in the swollen membrane at the elevated pressure, it took a much longer time ( 3,000 s) for the permeation of Mixture 2 to reach the quasi-steady state.

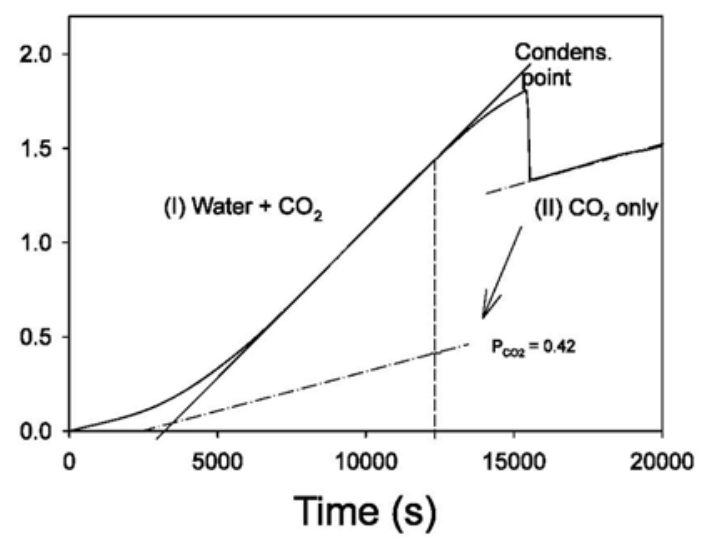

Figure 4: Permeation of Mixture 2 of water (9.4 torr) $-\mathrm{CO}_{2}$ (80.3 torr).

The steady state permeation fluxes were calculated for each species and listed in Table 2. As expected, pure water vapor presents the highest flux and the shortest time lag. When the partial pressure of $\mathrm{CO}_{2}$ increases (or the humidity of the feed decreases), the flux drops while the overall time lag increases significantly from Mixture 1 to 2 . Meanwhile, the permselectivity of water decreases significantly from infinity to 2.5 .

The overall permeation time lag of the mixture, L, was determined by the asymptote of the steady state pressure-time response in Section I of Figure 4. Ash
[16] pointed out that time lag of a binary system is a complicated issue. The time lag of each component, $\mathrm{CO}_{2}\left(\mathrm{~L}_{1}\right)$ and water $\left(\mathrm{L}_{2}\right)$, are related to the overall time lag as:

$$
L=j_{1} L_{1}+j_{2} L_{2}
$$

Where $j_{1}=J_{1} /\left(J_{1}+J_{2}\right)$ is the flux fraction ratio of species 1.

To determine the time lags for $\mathrm{CO}_{2}\left(\mathrm{~L}_{2}\right)$, we need the information of its steady state flux (which can be derived from the pressure time gradient of $\mathrm{CO}_{2}$ in Section II) as well as its partial pressure at certain time t. Therefore, $\mathrm{CO}_{2}$ concentration (or molar fraction, $\mathrm{y}_{\mathrm{i}}$ ) in the downstream vessel is needed for the calculation of its partial pressure $\left(P_{i}=P_{\text {total }} \times y_{i}\right)$ at time t. Although $y_{i}$ can be accurately analyzed using GC or MS for a single point, but this approach deviates from the purpose of this technology (even it is advantageous to the diffusion cell in that it only requires the measurement of a single point). Instead, we propose a simplified approach of:

$$
y_{i}=\frac{N_{i}}{N_{\text {total }}}=\frac{\int_{0}^{t} J_{i}(t) d t}{\sum_{i=1}^{2} \int_{0}^{t} J_{i}(t) d t} \approx \frac{J_{i}}{J_{\text {total }}}
$$

where $\mathrm{N}$ is the number of moles in the downstream vessel, $t$ is permeation time, and $\mathrm{J}_{\mathrm{i}}$ is steady state flux of component $\mathrm{i}$. The schematic method of deriving time lag of each component is demonstrated in Figure $\mathbf{4}$ and listed in Table 2. In brief, the slope of Section I gives the overall flux while the slope in Section II gives the flux of $\mathrm{CO}_{2}$. The $\mathrm{CO}_{2}$ molar fraction was calculated as 0.286 with Equation (3), which is a good approximation when permeation time $(\sim 12,500 \mathrm{~s})$ is >> overall time lag $(\sim 3,200 \mathrm{~s})$. At the downstream pressure of $1.5 \mathrm{torr}$, the partial pressure of $\mathrm{CO}_{2}$ is $\sim 0.42$ torr. The $\mathrm{CO}_{2}$ time lag is then determined by parallel shifting the asymptote of $\mathrm{CO}_{2}$ in Section II to this point $(\mathrm{P}=0.42$ torr, $\mathrm{t}=12,500 \mathrm{~s}$ ). As the results, the time lag for $\mathrm{CO}_{2}$

Table 2: Permeation Property of Chitosan-POSS Nanocomposite Membrane

\begin{tabular}{|c|c|c|c|c|c|}
\hline & & & & \multicolumn{2}{|c|}{ Mixture 2 } \\
\cline { 3 - 6 } & Pure $\mathrm{H}_{2} \mathrm{O}$ & Mixture 1 & Overall & $\mathrm{H}_{2} \mathrm{O}$ & $\mathrm{CO}_{2}$ \\
\hline \hline Time lag $(\mathrm{s})$ & & & $3,270.0$ & 3,578 & 2,500 \\
\hline Steady flux $\left(\mathrm{mol} / \mathrm{m}^{2} / \mathrm{s}\right) \times 10^{5}$ & 3.80 & 0.0 & 0.35 & 0.25 & 2.50 \\
\hline Perm-selectivity $\left(\mathrm{J}_{\mathrm{H} 2 \mathrm{O}} / \mathrm{J}_{\mathrm{CO} 2}\right)$ & - & $\infty$ & & 0.10 \\
\hline
\end{tabular}


Table 3: Proposed Cold Trap Temperature for Various Gas Mixtures

\begin{tabular}{|c|c|c|c|c|}
\hline Mixtures & $\mathbf{C H}_{4} / \mathbf{N}_{2}$ & $\mathbf{C O}_{2} / \mathbf{C H}_{\mathbf{4}}$ & $\mathbf{H}_{2} \mathbf{O} / \mathbf{H y d r o c a r b o n s}$ & $\mathbf{H}_{2} \mathbf{S} / \mathbf{C H}_{4}$ \\
\hline \hline Temperature $\left({ }^{\circ} \mathrm{C}\right)$ & $\begin{array}{c}-196 \\
\left.\text { (liquid } \mathrm{N}_{2}\right)\end{array}$ & $\begin{array}{c}-164 \text { or }-196 \\
\left.\text { (liquid } \mathrm{CH}_{4} \text { or liquid } \mathrm{N}_{2}\right)\end{array}$ & -30 to -50 & -196 \\
(liquid $\left.\mathrm{N}_{2}\right)$ & \\
\hline
\end{tabular}

was found to be $2,500 \mathrm{~s}$ by the direct plotting. The time lag of water is calculated from Equation (1).

The purpose of the above time lag analysis is to demonstrate the simplicity and feasibility of this technology. For the accurate study of a practical system, two issues need to be taken into account: 1) the vapor-gas system is generally not ideal at cryogenic temperature, and 2) the gaseous $\mathrm{CO}_{2}$ may adsorb onto the tiny ice crystals formed in the downstream vessel. The first issue can be solved by invoking the use of the equation of state for real gases, e.g. Peng-Robinson or Virial equations, in calculating the exact values. For the second issue, Adamson and Jone have demonstrated that $\mathrm{CO}_{2}$ adsorbs very marginally on ice crystals even at a much lower temperature $\left(<-70^{\circ} \mathrm{C}\right)$ while the formation of clathrate requires a considerably high pressure [17].

The temperature of the downstream vessel should be kept constant during the experiment. In our system, the vessel is made of stainless steel and was submerged in a large volume of coolant circulated by a powerful thermosat (Model: LAUDA Proline RD 845; Temperature resolution: $0.01^{\circ} \mathrm{C}$; Cooling power: 80 $\mathrm{kW})$. No temperature variation was detected in the cold trap during the experiments.

By varying the cold-trap temperature, this technology can be conveniently adapted to study the permeation/mass transport of other gas mixtures using the similar time lag analysis. The corresponding coldtrap temperatures are proposed for a number of important gas/vapor mixtures in Table $\mathbf{3}$.

\section{CONCLUSIONS}

The permeation of vapor-gas mixture can be conveniently studied by the proposed time-lag experimental and analytical methods. It is convenient and useful in studying the separation of natural gas, bio-gas, and flue gas, etc., of which the boiling points of the components are very different.

\section{ACKNOWLEDGEMENT}

This work is supported by the Gas Research Center of Petroleum Institute. Project No. GRC010.

\section{REFERENCES}

[1] Frisch HL. The Time Lag in Diffusion. 1957. p. 93-5.

[2] Ash R, Espenhahn SE, Whiting DEG. Transport through a slab membrane governed by a concentration-dependent diffusion coefficient: Part II. The four time-lags for some particular $\mathrm{D}(\mathrm{C})$. Journal of Membrane Science. 2000;166(2):281-301.

http://dx.doi.org/10.1016/S0376-7388(99)00272-0

[3] Galiatsatou P, Kanellopoulos NK, Petropoulos JH. Comprehensive time-lag measurement as a diagnostic and analytical tool for non-Fickian transport studies: a salient porous barrier-gaseous permeant test case. Physical Chemistry Chemical Physics. 2006;8(32):3741-8. http://dx.doi.org/10.1039/b605752g

[4] Rutherford SW, Do DD. Review of time lag permeation technique as a method for characterisation of porous media and membranes. Adsorption. 1997;3(4):283-312. http://dx.doi.org/10.1007/BF01653631

[5] Wang K. Gas permeation in hollow fiber membranes with nonlinear sorption isotherm and concentration dependent diffusion coefficient. Journal of Membrane Science. 2005;267(1-2):99-103.

http://dx.doi.org/10.1016/j.memsci.2005.07.037

[6] Chen J, Loo LS, Wang K, Do DD. The structural characterization of a CMS membrane using Ar sorption and permeation. Journal of Membrane Science. 2009;335(1-2):14. http://dx.doi.org/10.1016/j.memsci.2009.03.008

[7] Wang K. Diffusion anomaly and blind pore character in carbon molecular sieve membrane. Chemical Engineering Science. 2007;62(14):3654-9. http://dx.doi.org/10.1016/j.ces.2007.03.032

[8] Ruthven DM. Principles of adsorption and adsorption processes: John Wiley \& Sons; 1984. 464 p.

[9] Despond S, Espuche E, Domard A. Water sorption and permeation in chitosan films: Relation between gas permeability and relative humidity. Journal of Polymer Science Part B: Polymer Physics. 2001;39(24):3114-27. http://dx.doi.org/10.1002/polb.10064

[10] Liu L, Chakma A, Feng X. Gas permeation through waterswollen hydrogel membranes. Journal of Membrane Science. 2008;310(1-2):66-75 http://dx.doi.org/10.1016/j.memsci.2007.10.032

[11] Xu D, Loo LS, Wang K. Pervaporation performance of novel chitosan-POSS hybrid membranes: Effects of POSS and operating conditions. Journal of Polymer Science Part B: Polymer Physics. 2010;48(21):2185-92.

http://dx.doi.org/10.1002/polb.22100

[12] Mathew AP, Laborie M-PG, Oksman K. Cross-Linked Chitosan/Chitin Crystal Nanocomposites with Improved Permeation Selectivity and $\mathrm{pH}$ Stability. Biomacromolecules. 2009;10(6):1627-32.

http://dx.doi.org/10.1021/bm9002199

[13] Wang K, Suda H, Haraya K. The characterization of CO2 permeation in a CMSM derived from polyimide. Separation and Purification Technology. 2003;31(1):61-9. http://dx.doi.org/10.1016/S1383-5866(02)00154-5 
[14] Geankoplis CJ. Transport Processes and Separation Process Principles. New Jersey: Prentice Hall Professional Technical Reference; 2003. 1026 p.

[15] El-Azzami LAR. $\mathrm{CO}_{2}$ SELECTIVE MEMBRANE FOR FUEL CELL APPLICATIONS. Doctoral Dissertations. 2006.
[16] Ash R. A note on the time-lags for the transport of gas mixtures. Journal of Membrane Science. 1999;161(1-2):13942.

http://dx.doi.org/10.1016/S0376-7388(99)00102-7

[17] Adamson AW, Jones BR. Physical adsorption of vapors on ice. IV. Carbon dioxide. Journal of Colloid and Interface Science. 1971;37(4):831-5.

http://dx.doi.org/10.1016/0021-9797(71)90364-X 